\title{
What is the impact of covid-19 pandemic era on Pregnant Women sero-positivity for Syphilis among women attending antenatal care in India and number of babies diagnosed with Congenital Syphilis?
}

Dr Piyush Kumar ( $\nabla$ drpiyush003@gmail.com )

Health Department, Government of Bihar, India https://orcid.org/0000-0001-9857-478X

\section{Research Article}

Keywords: syphilis, COVID-19, sero-prevalence, pregnant women, antenatal care, newborn

Posted Date: January 27th, 2022

DOI: https://doi.org/10.21203/rs.3.rs-1302581/v1

License: @ (i) This work is licensed under a Creative Commons Attribution 4.0 International License. Read Full License 


\section{Abstract}

Sexually transmitted infections (STIs) still continue to be a major public health problem globally, affecting the quality of life as well as causing serious morbidity and mortality. STIs have a direct and significant impact on reproductive and child health. They can directly cause infertility, cancers as well as pregnancy complications, and indirectly affects individual economies. The information on the number of PW found to be sero positive for Syphilis among women attending antenatal care in India and number of babies diagnosed with Congenital Syphilis is collected from HMIS electronic records of MoHFW, Government of India with key objective to know about the impact of covid-19 era i.e. 2020 and 2021 on prevalence of syphilis by comparing it with the pre pandemic era of 2018 and 2019. I collected sero positivity data for Syphilis among women attending antenatal care in India and number of babies diagnosed with Congenital Syphilis across 36 states and union territories of India including all health facilities viz. public, private, rural, urban health facilities. The data is collected, observed and analyzed with Microsoft office software. Among 254705.2 averages per month number of PW (pregnant women) tested using POC test for Syphilis, 2144.4 averages per month were sero positive for Syphilis giving a sero-prevalence of $0.84 \%$ in 2021 (Jan to May). Of 175579.75 averages per month number of PW tested using POC test for Syphilis, $\mathbf{8 5 5 . 5 8}$ averages per month were sero positive for Syphilis giving a seroprevalence of $0.49 \%$ in $\mathbf{2 0 2 0}$ (Jan to Dec). Of 53313.66 averages per month number of PW tested using POC test for Syphilis, $\mathbf{4 1 9 . 3 3}$ averages per month were sero positive for Syphilis giving a sero-prevalence of $0.79 \%$ in 2019 (Jan to Dec). Of 11364.75averages per month number of PW tested using POC test for Syphilis, 339.08 averages per month were sero positive for Syphilis giving a sero-prevalence of $2.98 \%$ in 2018 (Jan to Dec).

\section{Introduction}

Sexually transmitted infections (STIs) still continue to be a major public health problem globally, affecting the quality of life as well as causing serious morbidity and mortality. STIs have a direct and significant impact on reproductive and child health. They can directly cause infertility, cancers as well as pregnancy complications, and indirectly affects individual economies. On daily basis a million (10 lakh) STIs are acquired, in year 2012, 357 million new cases of curable STIs which includes gonorrhoea, chlamydia, syphilis and trichomoniasis occurred mainly among 15- to 49-year-olds individuals globally, out of which $\mathbf{5 . 6}$ million cases were of syphilis [1]. Syphilis is a STI caused by bacterial infection of Treponema pallidum. It is usually transmitted during sexual contact with infectious lesions present on the mucous membranes or abraded epidermis, via blood transfusion, or vertical-transplacentally during pregnancy to the foetus. Vertical transmission of syphilis i.e. congenital syphilis is usually life-threatening to the fetus if maternal infection is not detected on time and treated early in the pregnancy. The work from home and lockdowns for covid-19 control can increase the prevalence and incidence of STI (hypothesis) as the chances for sexual relation is quite possibly increased due to availability and opportunity but this will be decided by multiple factors related to the transmission of infection. Discussing all the aspects, patho-physiology as well as clinical features etc., is not possible in this single 
article.Undertaking sero-sampling during the covid-19 pandemic is quite difficult when travel and household access are restricted by Covid control measures. Pregnant mothers and newborns continue to seek health services throughout the pandemic due to their special needs. Serological tests are simple to perform at ANC visits and POC test for Syphilis can be done with the residual blood volumes of samples collected for routine ANC clinical screening for maternal infectious diseases and anaemia. Planning and provision of antenatal health care during pandemic like COVID-19 pose significant logistical and clinical challenges. In January 2020 first covid-19 case was documented in India []. Hence period from January 2020 onwards is counted as pandemic era which is still going on and period before January 2020 i.e. up to December 2019 is calculated as pre-pandemic era for this research study.

\section{Aim And Objective}

To assess and compare the trend in sero-prevalence and number of cases of syphilis throughout the pandemic years i.e. 2020, 2021 and two previous years 2019, 2018 with key objective to find out the trends of disease occurrence in pregnant women and newborn by analysing sero positivity for Syphilis among pregnant women attending ANC clinic at different (public-private-rural-urban) health facilities in India and number of babies diagnosed with Congenital Syphilis.

\section{Methodology}

This is a cross - sectional retrospective mixed study. The information on the number of PW found to be sero positive for Syphilis among women attending antenatal care in India and number of babies diagnosed with Congenital Syphilis is collected from HMIS electronic records of MoHFW, Government of India. I collected sero positivity data for Syphilis among women attending antenatal care in India and number of babies diagnosed with Congenital Syphilis across 36 states and union territories of India including all health facilities viz. public, private, rural, urban health facilities. The data is collected, observed and analyzed with Microsoft office software.

\section{Data Availability}

The data for study is obtained from electronic records of HMIS of MoHFW (Ministry of Health and Family Welfare), Government of India. The link for the source is given below:-

https://hmis.nhp.gov.in/\#!/standardReports

\section{Results}

Among 254705.2 averages per month number of PW tested using POC test for Syphilis, 2144.4 averages per month were sero positive for Syphilis giving a sero-prevalence of $0.84 \%$ in 2021(Jan to May) see figure - 1, 2, 3. Of 175579.75 averages per month number of PW tested using POC test for Syphilis, $\mathbf{8 5 5 . 5 8}$ averages per month were sero positive for Syphilis giving a sero-prevalence of $0.49 \%$ in 2020 (Jan 
to Dec). Of 53313.66 averages per month number of PW tested using POC test for Syphilis, $\mathbf{4 1 9 . 3 3}$ averages per month were sero positive for Syphilis giving a sero-prevalence of $0.79 \%$ in $\mathbf{2 0 1 9}$ (Jan to Dec). Of 11364.75averages per month number of PW tested using POC test for Syphilis, $\mathbf{3 3 9 . 0 8}$ averages per month were sero positive for Syphilis giving a sero-prevalence of $2.98 \%$ in 2018 (Jan to Dec), see table 1 and 2.

The total number of babies diagnosed with Congenital Syphilis was 3801, 3372, 4909, 2424 during the years 2018-2019-2020-2021- respectively which shows that number increased during the first pandemic year 2020 and data for the second pandemic year is only up to May-2021 hence the result is pending and will be updated in next version after availability of data. The total number of PW tested using POC test for Syphilis during Jan-May 2021 was 1273526 whereas for the year 2020, 2019, 2018 it was 2106957, 639764 , and 136377 respectively. Since the data for 2021 is not available up to Dec 2021 from an accredited source the author has taken average numbers per month for various comparisons. This research study revealed that there is increase in averages per month number of PW tested using POC test for Syphilis and also there is increase in number of women averages per month sero positive for Syphilis during pandemic era using this test. The sero-prevalence decreased in all years as compared to 2018. This research study revealed that in 2019 maximum averages per month number of PW tested using other test for Syphilis whereas maximum numbers of women averages per month sero positive were found in 2021 for Syphilis using other test. The sero-prevalence of syphilis in PW tested using other test for Syphilis decreased in all years as compared to 2018 see figure-4, 5, and 6.Figure 7 show that Year-wise maximum number of syphilis positive pregnant women treated for syphilis were reported in 2021. Figure -8 shows that average number of babies per month diagnosed with congenital syphilis increased in pandemic era whereas Figure -9 shows that average number of babies per month treated with congenital syphilis decreased in pandemic era.

Table -1 - Average per month Comparison of various indicators for Syphilis 


\begin{tabular}{|c|c|c|c|c|}
\hline Indicator & $\begin{array}{l}\text { Average per } \\
\text { Month up to May } \\
2021\end{array}$ & $\begin{array}{l}\text { Average per } \\
\text { Month } \\
2020\end{array}$ & $\begin{array}{l}\text { Average per } \\
\text { Month } \\
2019\end{array}$ & $\begin{array}{l}\text { Average per } \\
\text { Month } \\
2018\end{array}$ \\
\hline $\begin{array}{l}\text { Number of PW tested using POC } \\
\text { test for Syphilis }\end{array}$ & 254705.2 & 175579.8 & 53313.67 & 11364.75 \\
\hline $\begin{array}{l}\text { Out of above, number of PW } \\
\text { found sero positive for Syphilis }\end{array}$ & 2144.4 & 855.5833 & 419.3333 & 339.0833 \\
\hline $\begin{array}{l}\text { Number of pregnant women } \\
\text { tested for Syphilis }\end{array}$ & 704464.8 & 685118.3 & 830475.1 & 634827.8 \\
\hline $\begin{array}{l}\text { Number of pregnant women } \\
\text { tested found sero positive for } \\
\text { Syphilis }\end{array}$ & 3983.2 & 3358.583 & 3588.167 & 3758.917 \\
\hline $\begin{array}{l}\text { Number of syphilis positive } \\
\text { pregnant women treated for } \\
\text { Syphilis }\end{array}$ & 2019.6 & 1127.5 & 1242.583 & 1280.167 \\
\hline $\begin{array}{l}\text { Number of babies diagnosed with } \\
\text { Congenital Syphilis }\end{array}$ & 484.8 & 409.0833 & 281 & 316.75 \\
\hline $\begin{array}{l}\text { Number of babies treated for } \\
\text { Congenital Syphilis }\end{array}$ & 325.2 & 306.1667 & 408.3333 & 1335.75 \\
\hline
\end{tabular}

Table -2- Grand Total of various indicators for syphilis for comparing different years 


\begin{tabular}{|llllll|}
\hline Indicator & $\begin{array}{l}\text { Grand } \\
\text { Total Jan- } \\
\text { May 2021 }\end{array}$ & $\begin{array}{l}\text { Grand } \\
\text { Total Jan- } \\
\text { Dec 2020 }\end{array}$ & $\begin{array}{l}\text { Grand } \\
\text { Total Jan- } \\
\text { Dec 2019 }\end{array}$ & $\begin{array}{l}\text { Grand } \\
\text { Total Jan- } \\
\text { Dec 2018 }\end{array}$ & $\begin{array}{l}\text { Total } \\
\text { number in } \\
\text { four years }\end{array}$ \\
\hline $\begin{array}{l}\text { Number of PW tested using } \\
\text { POC test for Syphilis }\end{array}$ & 1273526 & 2106957 & 639764 & 136377 & 4156624 \\
\hline $\begin{array}{l}\text { Out of above, number of PW } \\
\text { found sero positive for } \\
\text { Syphilis }\end{array}$ & 10722 & 10267 & 5032 & 4069 & 30090 \\
\hline $\begin{array}{l}\text { Number of pregnant women } \\
\text { tested for Syphilis }\end{array}$ & 3522324 & 8221419 & 9965701 & 7617933 & 29327377 \\
$\begin{array}{l}\text { Number of pregnant women } \\
\text { tested found sero positive for } \\
\text { Syphilis }\end{array}$ & 19916 & 40303 & 43058 & 45107 & 148384 \\
\hline $\begin{array}{l}\text { Number of syphilis positive } \\
\text { pregnant women treated for } \\
\text { Syphilis }\end{array}$ & 10098 & 13530 & 14911 & 15362 & 53901 \\
\hline $\begin{array}{l}\text { Number of babies diagnosed } \\
\text { with Congenital Syphilis }\end{array}$ & 2424 & 4909 & 3372 & 3801 & 14506 \\
\hline $\begin{array}{l}\text { Number of babies treated for } \\
\text { Congenital Syphilis }\end{array}$ & 1626 & 3674 & 4900 & 16029 & 26229 \\
\hline
\end{tabular}

\section{Discussion}

The average number of PW tested per month using POC test for Syphilis increased gradually from year 2018 continuously see figure 1 and table 1 . There is also an increase in average number of PW found sero positive for Syphilis which indicates that increasing number of tests have detected more syphilis cases as well as less number of testing may have left several cases. It is frequently asked that which test is most diagnostic for syphilis. The Direct fluorescent antibody test for T pallidum is considered as the most specific test for the diagnosis of syphilis when lesions are present. This test utilize fluorescein isothiocyanate-labelled antibody which is specific to pathogenic Treponema [2]. Very simple rapid tests for detection of syphilis are also commercially available. These are popularly known as point of care (POC) tests which can be performed without laboratory setting and with minimal training as well as no special equipment is required. POC are done using a small amount of whole blood collected by a finger prick [3].

\section{Study Strength And Limitation}

This is a cross-sectional retrospective research study based on secondary data which was one of the main limitations of this research study. Another limitation is availability of data from any other accredited and established source recognized worldwide is not available. The main strength is that the whole study 
is based on real time based accredited government data sources and this kind of research study is unique and not available for the context of India as found by the researcher of this novel study.

\section{Conclusion And Recommendation}

The WHO recommends screening of all pregnant women for syphilis at first antenatal care visit [1]. In pregnant women with early syphilis, the WHO STI guideline recommends benzathine penicillin G 2.4 million units once intramuscularly over no treatment.

\section{Declarations}

-This version of paper has not been previously published in any peer reviewed journal and is not currently under consideration by any journal. The document is Microsoft word with English (United States) language \& 2103 words excluding reference and declaration (2382 words Total including all).

- Ethics approval and consent to participate: Not applicable. This study has not involved any human or animals in real or for experiments. The submitted work does not contain any identifiable patient/participant information.

-Consent for publication: The author provides consent for publication.

-Availability of data and materials: Electronic records from HMIS (health management information system) of MoHFW (ministry of health and family welfare), Government of India.

-Conflicts of Interest/ Competing Interest: There are no conflicts / competing of interest

- Funding-Self sponsored. No aid taken from individual or agency etc.

- Authors' contributions: The whole work is done by the Author - Dr Piyush Kumar, M.B.B.S., E.M.O.C., P.G.D.P.H.M., -Senior General Medical Officer- Bihar Health Services- Health Department- Government of Bihar, India.

- Acknowledgements-I am thankful to Advocate Anupama my wife and daughters Aathmika-Atheeva for cooperation.

- Author information: The author is currently working as Senior General Medical Officer for the government of Bihar.

-Financial Support \& sponsorship: Nil

-Author contact information

Department of Health, Government of Bihar, MOBILE -

+919955301119/+917677833752, Email drpiyush003@gmail.com 


\section{References}

1. WHO guideline on syphilis screening and treatment for pregnant women https://

2. Ratnam S. (2005). The laboratory diagnosis of syphilis. The Canadian journal of infectious diseases \& medical microbiology = Journal canadien des maladies infectieuses et de la microbiologie medicale, 16(1), 45-51. https://doi.org/10.1155/2005/597580

https://www.ncbi.nlm.nih.gov/pmc/articles/PMC2095002

3. WHO - Sexual and reproductive health - The use of rapid syphilis tests- WHO reference number.

WHO/TDR/SDI/06.1 https://www.who.int/reproductivehealth/publications/rtis/TDR_SDI_06_1/en/

\section{Figures}

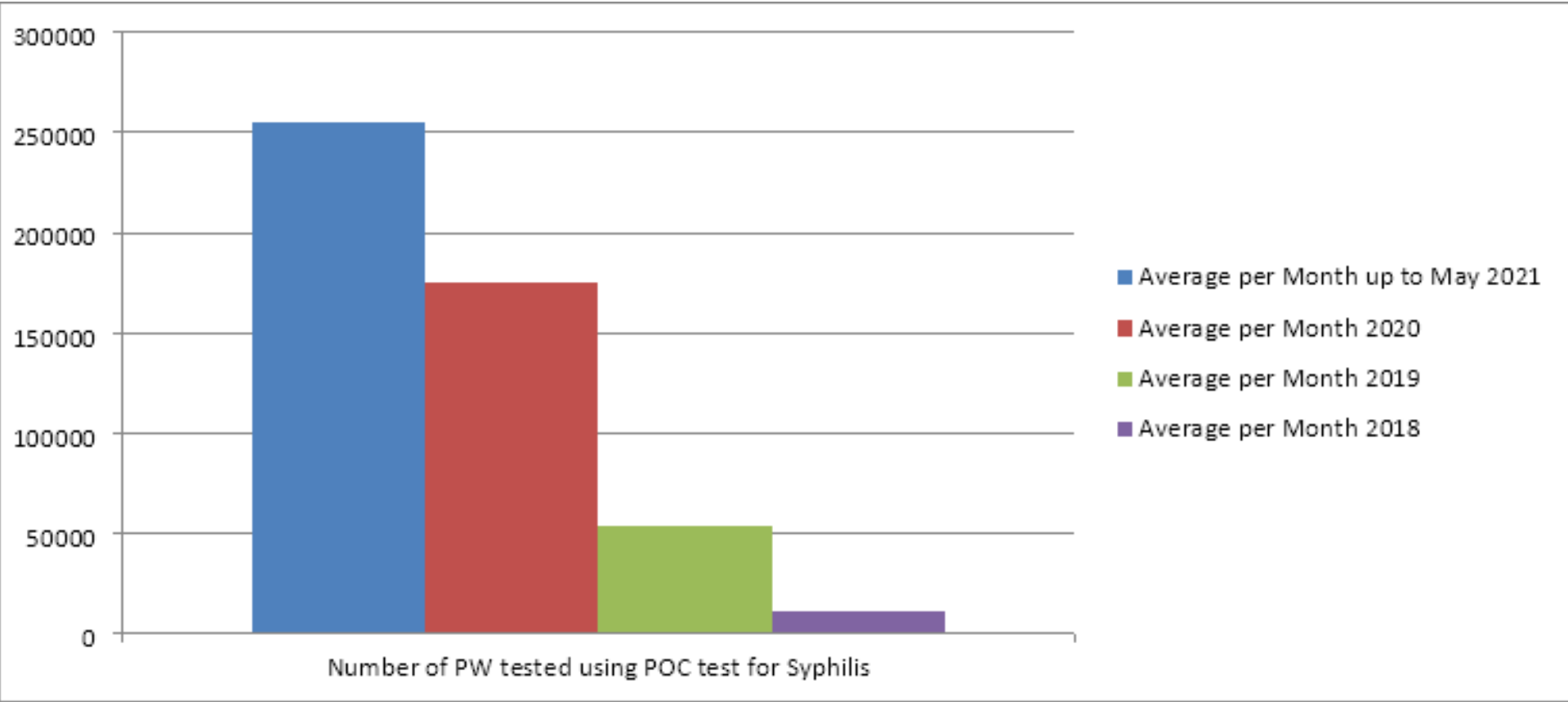

Figure 1

Average number of women per month tested for syphilis using POC test

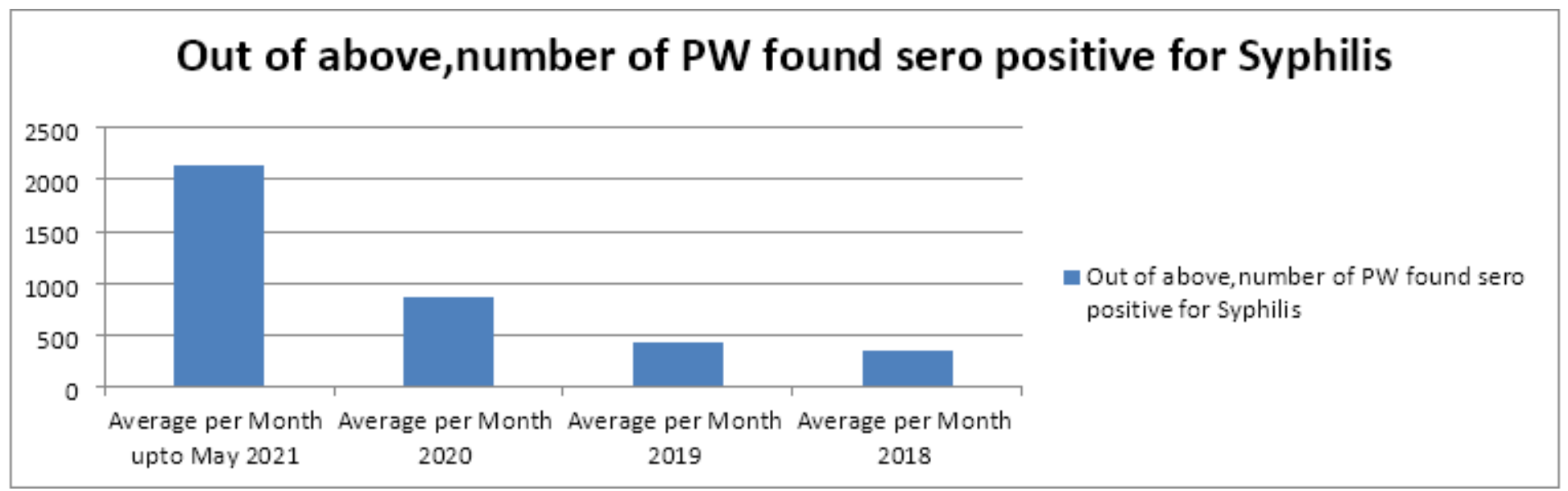


Figure 2

Average per month in different years- number of pregnant women (PW) found sero- positive for syphilis using POC test

\section{Sero-prevalence of Syphilis in different year}

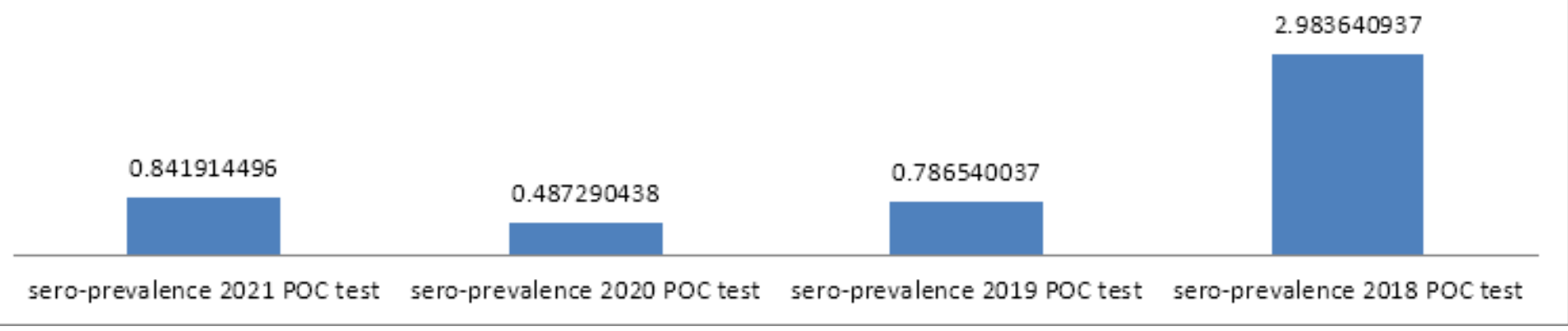

\section{Figure 3}

Sero-prevalence of syphilis in PW tested using POC test for Syphilis

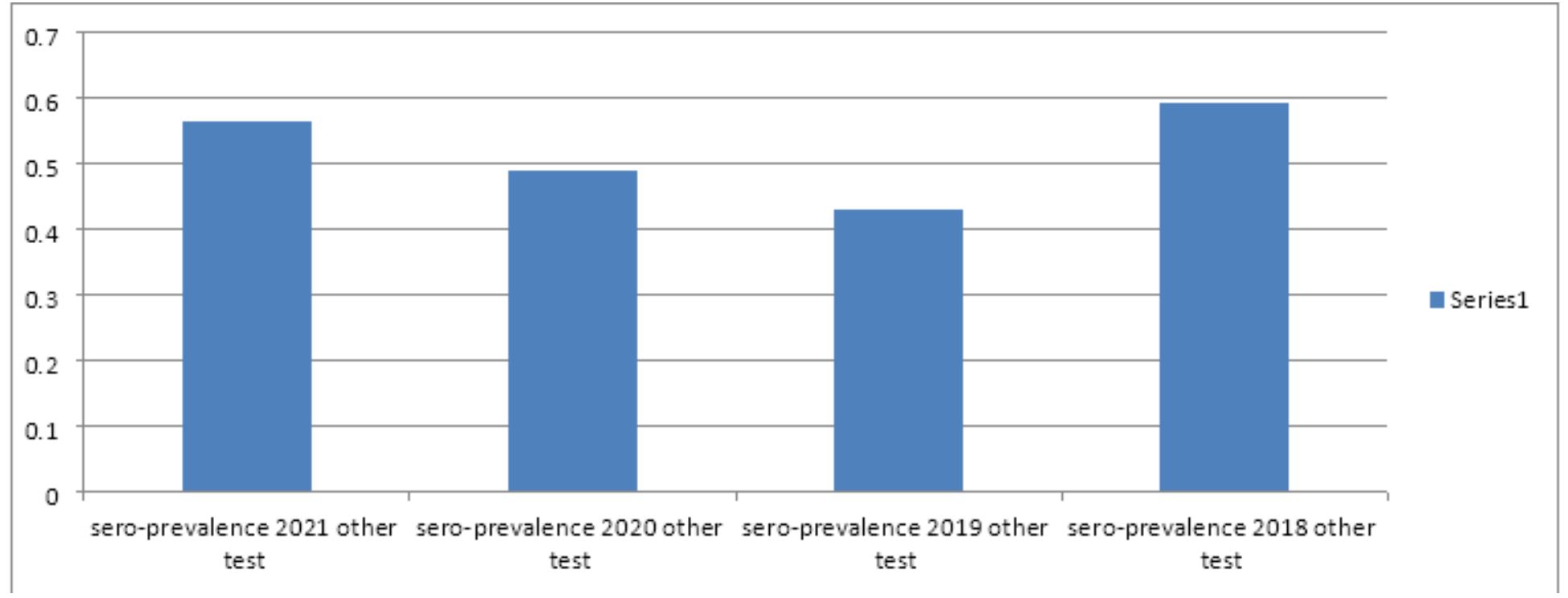

\section{Figure 4}

Sero-prevalence of syphilis in PW tested using other test for Syphilis 


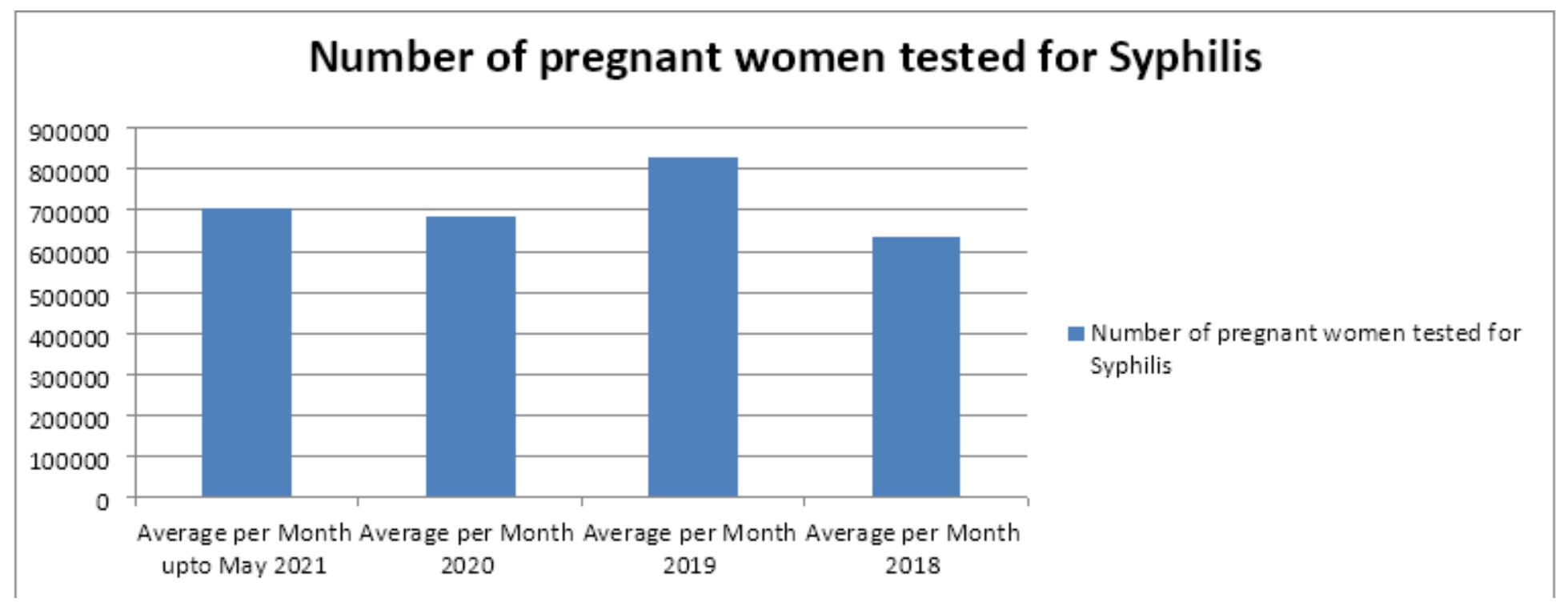

Figure 5

Number of PW tested using other test for Syphilis

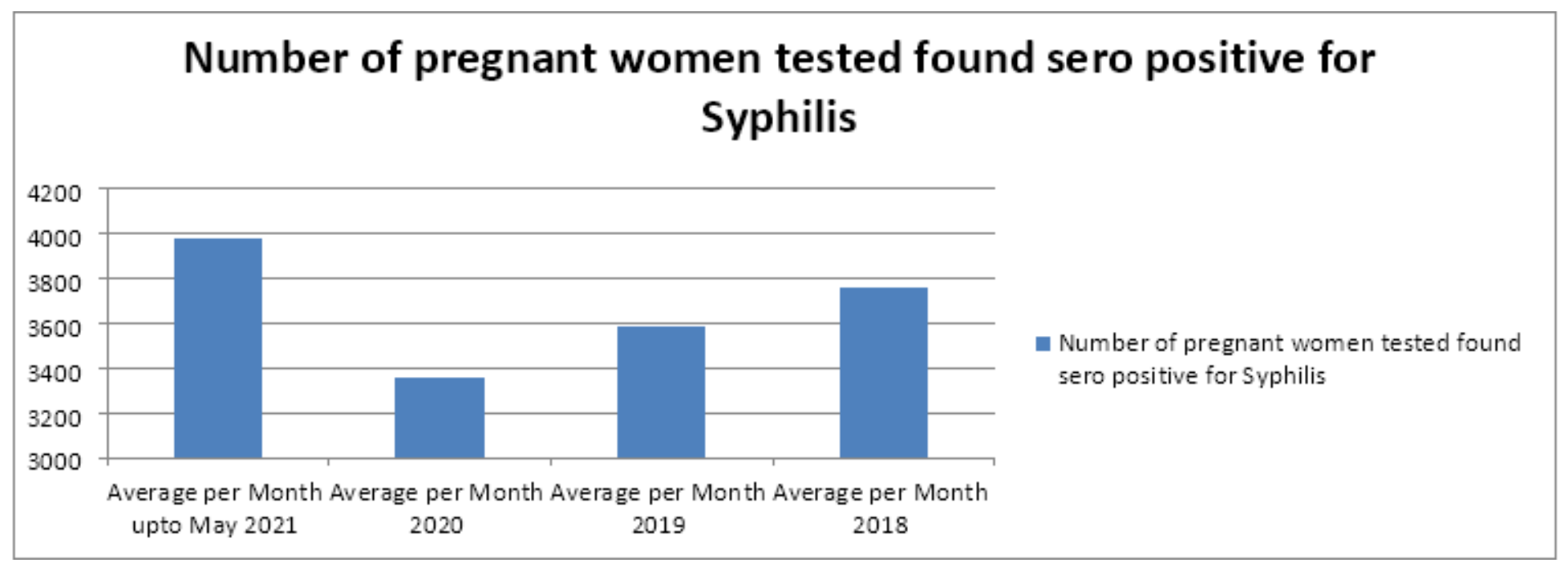

Figure 6

number of pregnant women tested by test other than POC and found sero-positive 


\section{Number of syphilis positive pregnant women treated for Syphilis}

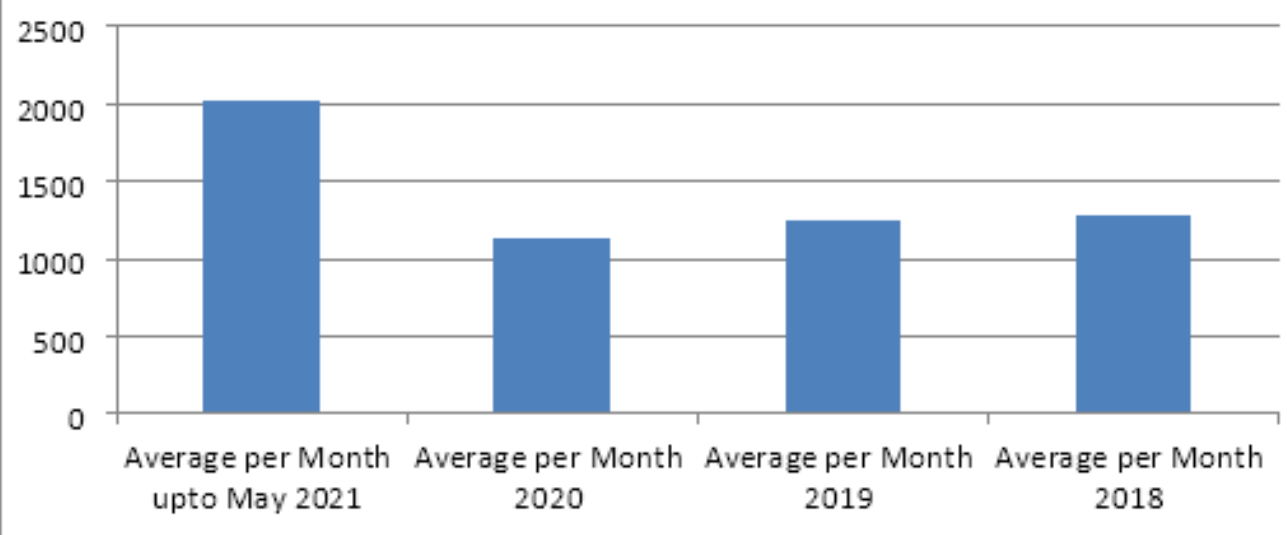

- Number of syphilis positive pregnanat women treated for Syphilis

Figure 7

Year-wise number of syphilis positive pregnant women treated for syphilis

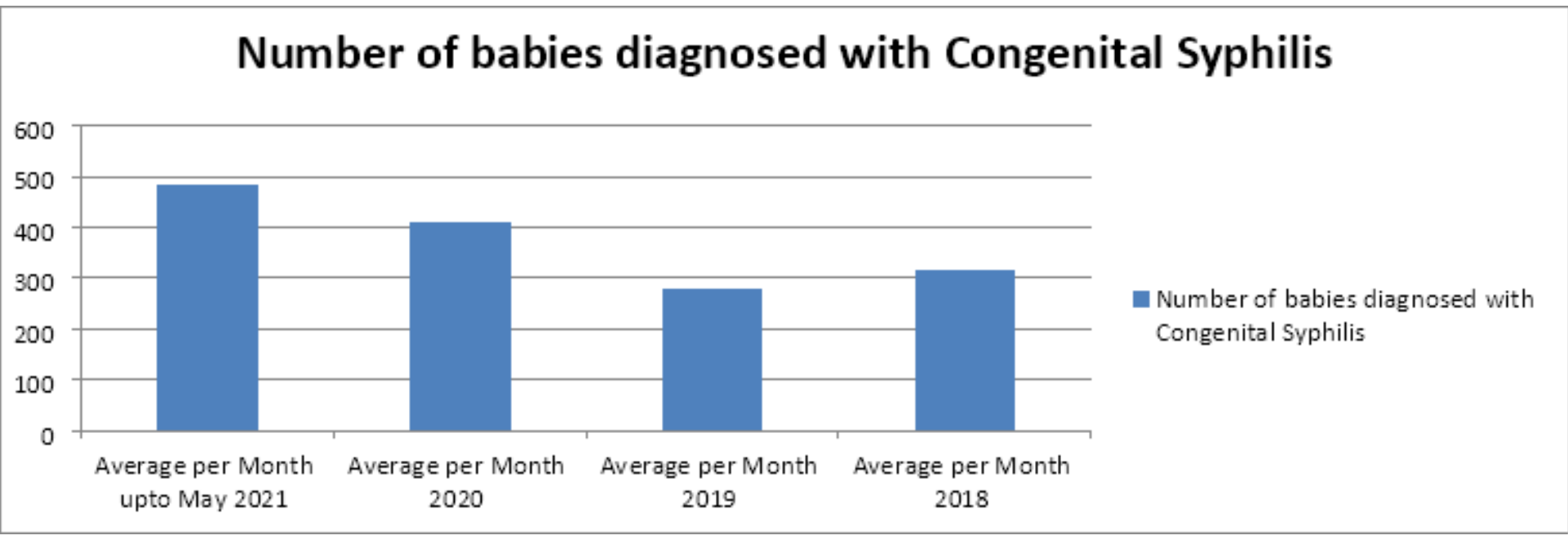

Figure 8

average number of babies per month diagnosed with congenital syphilis. 


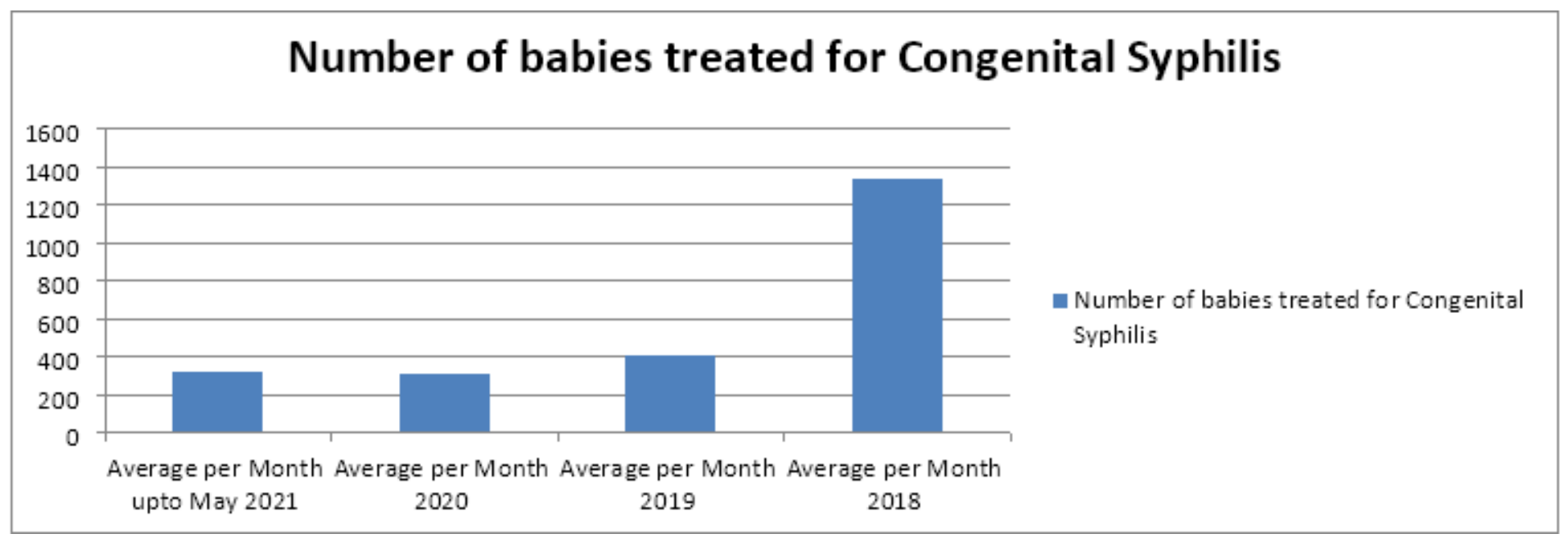

Figure 9

average number of babies per month treated with congenital syphilis 